\title{
A Study of Verbal Reasoning and ESL Vocabulary Learning from a Psycholinguistic Perspective
}

\begin{abstract}
:
The present study is mainly interested in finding out the impact of verbal reasoning abilities; more precisely that of lexical inference, in improving ESLvocabulary learning. A group of twenty (20)female learners (aged between 19 and 21 years old), of about 220 third year learners/ LMD systemat the English department/ the University of Frère Mentouri/ Constantine1, were used in the study. The participantswere tested forthe dependent variable that was rated from Cloze Procedure Format activitiesthat were administered during the year 2014-2015, by the end ofsomelectures on Psychopedagogy. Every class, the learners were assigned a text in the latter fieldand had to fill in the blanks using provided technical termslearnt in the same lecture. The collected data was analyzed, after that,and results show that lexical inference, as a cognitive skill, corresponds to ESL technicalvocabulary learning.

Key words: lexical inference -ESL vocabulary acquisition mental lexicon.
\end{abstract}

\author{
Imane LAMRI \\ Faculty of Letters and Languages \\ Department of Foreign Languages \\ University of Mentouri \\ Constantine
}

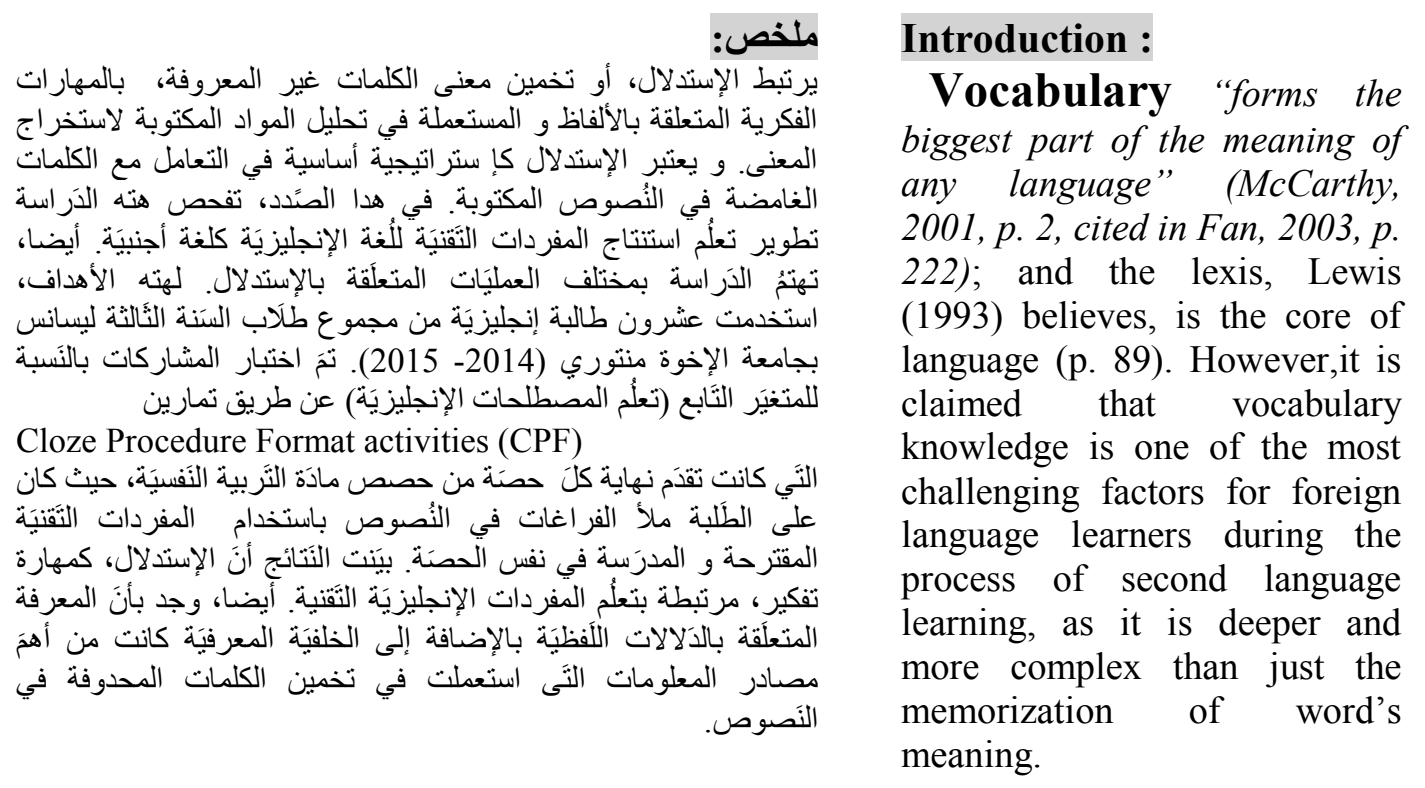


In the present time, the major idea in relation to the organization of lexicon is that words are stored in a well arranged interrelated network. However, the mental lexicon is a complex phenomenon, the reason why the exact nature of lexical knowledge has always perplexed researchers and teachers. This is not surprising as a lexicon can hold several thousands of words connected differently to other words in the lexical network. In addition, those connections between words are not easy to explain obviously. For instance, red may be linked to words like spicy, satisfying, blood, etc; but illustrating the way these words are retained in the mental lexicon or the way they are connected to each other is not simple. Nippold (2004), a researcher interested in the domain of L1 development during childhood and adolescence defines the lexicon as a "mental dictionary of thousands of complex and lowfrequency words, co-existing in an elaborate semantic network" (p. 2). These words are related to reading and writing, and understanding the field of specific concepts, etc.

When it comes to vocabulary knowledge,second language vocabulary size is considered as one of the main factors that influence language learning generally, L2 readers, specifically, are not able to understand a whole text in case they cannot distinguish the words in that text. It has been proposed that word knowledge is related to reading comprehension and that readers with better vocabulary knowledge are better 'comprehenders' (Ulijn \& SalagerMeyer, 1998; Lemmon, 2004, cited in Yang, 2014, pp. 19-20). Yet, it not an easy matter to know every single word, mainly for ESL learners, to understand written discourse (or spoken discourse). So, how do ESL learners handle unfamiliar words while reading English texts?.

Recently, learning vocabulary in context is drawing significant interest (Milton, 2009, p. 229). One most commonly used strategy (reasoning method) that learners employ to deduce the meaning of unknown words from written material is word-meaning inference/ lexical inference; or what Haastrup (1991) named "informed guess" (p. 40) as it is built mainly on top-down cognitive processes that relies on using information previously stored in our memory (Akpinar, 2013, p. 1).

\section{Cognitive Perspective on L2 Vocabulary Learning}

According to Ellis (1995), acognitive theory of L2 acquisition, basedon the theory of processing, thinks of linguistic knowledge as being guided by the same rules as other kinds of learning, yet perhaps more intricate in nature (Takac, 2008, p. 28). Emphasis is placed on 'meaningful learning', i.e. learning with understanding which is not manifested in behaviour (Takac, 2008, p. 26), but which can be described by Ausubel (1967) as "...conscious experience that emerges when potentially meaningful signs, symbols, concepts... are related to and incorporated within a given individual's cognitive structure" (p. 10). In 
this sense, meaningful learning is opposed to rote learning that is based on repetition.

Ellis (2000) claimed thatthe cognitive theory describes L2 acquisition as an intricate cognitive skill which, like other similar skills, involves cognitive systems (like perception, memory, and information processing (Ellis, 2000, p. 175).As for Nation and $\mathrm{Gu}$ (2007), vocabulary learning needs memory, processing, storing, and using L2 words (output) (Nation \& Gu, 2007, p. 85). Repetition and use are two means to make retrieval easy (Baddeley, 1997, pp. 116-19).

\subsection{The Role of Memory in Vocabulary Learning and Acquisition}

When getting new information, the majority of it is forgotten right away, after which the process of forgetting decelerate. Thornbury (2002) has gathered a list of rules that ease the transmission of information into LTM. These involve several times of coming across a lexical item, if possible at spaced periods, recall and use of a lexical items, cognitive depth (getting brain working; from comprehension to using, analyzing, evaluating, creating) (cf. Schneider et al., 2002), affective depth (making it personal in some ways, getting the students to relate the language to their own life), imaging, use of mnemonics and conscious attention that is essential to recall a lexical item (Takac, 2008, pp. 10-1).

\subsection{The L2 Mental Lexicon}

\subsubsection{How the Mind Organizes Vocabulary}

In our mother tongue, we are capable of storing, retrieving, and using huge amount of words, but how all that happens rapidly? What processes are involved and are they similar in L1 and L2? (McCarthy, O'keeffe, \& Walsh, 2010, p. 101).

Searching words in the mind, or our mental lexicon, we can use observations of how language is used as a method to understand how words are stored and retrieved. Using the computer analogy, we can say that a lot relies on memory size and processor pace. However, it also relies on how we record, store and retrieve information. Moreover, we must not presume that the processes are alike in L1 and L2 (McCarthy et al., 2010, p. 101).

Different processes determine how words are organized in the mind: Input, storage, and retrieval: Input is about how words are recorded, storage concerns how words are retained, while retrieval has to do with recalling words (McCarthy et al., 2010, p. 102). For Krashen and Terrell (1983), second language learners acquire the language best if they are exposed to input that suit their competency level (McCarthy et al., 2010, p. 103).

Despite the fact that semantic relations between words are crucial for storage, words have private meaning for us. For example, if we were to depict a network for holidays, we would have something founded on our own 
experiences and knowledge of the world (e.g. beach, friends, family, etc) (McCarthy et al., 2010, p. 105).

In this situation, knowing a word involves linguistic, experimental, and world knowledge. It proposes that our storage of words is very linked to how we store memories and experiences. Instead of thinking of words as stored in the mind in an organized way, this outlook of storage proposes that we should think in relation with networks. In addition, this view identifies that every word -every network- is continually renovated as novel vocabulary is acquired. This theory of the way words are stored is usually called connectionism (McCarthy et al., 2010, p. 105).

One of the aspects of knowing a word is being capable ofretrieving (recalling) it when required. Retrieval varies depending on whether words are receptive or productive (McCarthy et al., 2010, p. 106). According to McCarthy (1990), receptive retrieval "involves matching spoken or written input to stored sound and orthographic patterns and their associated meanings" ( $p$. 43). This is why, for example, in a reading activity, it is crucial to get learners NOT to concentrate on each single word, but to just recognise words. (McCarthy et al., 2010, p. 106). Visual word recognition has to do with the processes by which readers distinguish written words. Recognizing a word permits a reader to use the word's semantics to decide about its meaning. (Strazny, 2005, p. 1155).

Productive retrieval signifies being capable of making more active use of a word, in a piece of writing, for example. Here, receptive and productive are not equivalents of passive and active, as these latter terms are sometimes kept for talking about the skills and the notion that 'reading is a passive, speaking is active' (McCarthy et al., 2010, p. 106).

\subsubsection{The Organisation and Development of the L2 Mental Lexicon}

L2 vocabulary growth is affected by the arrangement of mental lexicon. The mental lexicon, according to Hulstijn (2000), is "a memory system in which a vast number of words, accumulated in the course of time, has been stored" (p. 210). This organisation is thought to be systematized as it is the only justification for the truth that people are able, at a chocking speed, in huge amount of lexical items stocked in memory, to identify and recall the required lexical item. Human memory is so supple and it is capable of processing a huge amount of input, yet just in case it is methodically arranged (Takac, $2008 \mathrm{p}$. 11).

The mental lexicon provides various entries to knowledge; processes of word identification and word production stimulate more words than needed, just to form an ultimate choice and conceal excessive knowledge (Takac, 2008, p. 12).

Considering what has been said on the top, it is presumed that the position of a word in the mental lexicon should be symbolized by a three 
dimensional pattern, as McCarthy (1994) stated: “with phonological nets crossing orthographic ones and criss-crossing [intersecting] semantic and encyclopaedic nets" ( $p .41)$. Yet, the connections between single networks are so delicate and are able to detach. This is noticeable in situations when a speaker forgets about the pronunciation of a previously learnt word, though knows that it exists and what it signifies, etc. This case added to the truth that a speaker of a language can comprehend new forms, is usually thought of as proof sustaining the split between receptive and productive vocabulary (Takac, 2008, pp. 12-3).

According to Hulstijn (2000), likenesses and dissimilarities between L1 lexicon and L2 lexicon (s) can be recapitulated into four main hypotheses:

-the extended system hypothesis: L1 and L2 words are stored in the same store; -the dual system hypothesis: L1 and L2 words are stored separately;

-the tripartite hypothesis: alike words share the same store (like cognates), where language-specific words are stored in independent stores;

-the subset hypothesis: L1 words and L2 words are stored in two rather detached stores, which are themselves stored in a joint store

(Hulstijn, 2000, p. 14).

Meara (1986) ended up, on the basis of his scrutiny, that methods for word storage and treatment is different with L2 mental lexicon (comparing to L1). So, said Meara, learners use techniques inappropriate for that particular language, which can explain certain complexities in L2 learning (Takac, 2008, p. 14). Swan (1997) stated that one should end up that there are "... significant...differences between the L2 mental lexicon and the L1 mental lexicon for all language learners" ( $p .175)$.

\section{Technical Vocabulary}

Technical vocabularies are essentially words that are particular to a specific branch of learning (Nation, 2001, p. 198). They include words that are not really familiar in other fields or those which are part of high-frequency words, yet subject-specific (demand, supplyare used in economics). They are normally distinguished by semantic specification, resistant to semantic alteration, and lack of precise synonyms (Mudraya, 2006, pp. 238-9). Every dictionary of technical vocabulary includes less than a thousand words (Nation, 2001, p. 18).

And despite the fact that core words, academic words, and technical terms are depicted as if they were obviously independent, the borders between them are fuzzy (Yang, 1986; Mudraya, 2006; Beheydt, 2005, cited in Paquot, 2010, p. 13).

There are levels of "technicalness" relying on how limited a word is to a specific field.

Technical vocabulary is grouped into four types: 
1-The word seldom exists out of this specific area, like pixel, modem in computing. Hence, a person who knows these words is expected to be wellinformed of that domain too.

2-The word is used in and out of this specific area though with different significance. Excute for example (in computing).

3-The word form is used in and out of this area, however, the majority of its uses with a specific significance, though not all, are in this area. The particular significance it has in this area is easily understandable via its significance out of the field. For example, accused (in law), frequency (in Applied Linguistics), memory, window (in computing).

4-The word form is more familiar in this area than away. There is a slight or no particularity of significance, still a person well-informed in the area would have a more exact concept of its significance. Like judge (in law), print (in computing), and word, meaning (in Applied Linguistics).

(Nation, 2001, pp. 198-99).

Baker (1988) claims that this zone between core and technical vocabulary consists itself of many kinds of vocabulary:

1. Items which communicate ideas shared by all or many specialized fields, likefactor.

2. Items with a specialized meaning in a specific domain and a different meaning in general language (e.g. bug in computer science, solution in mathematics and chemistry).

3. Items which are not utilized in general language though have different technical meanings in various fields (e.g. morphological in linguistics, botany and biology).

4. General language items having constrained meanings in one or more fields. In botany, 'genes which are expressed have perceptible effects, i.e. are more visible physically,

Contrary to being masked. Expressed in botany is not related with emotional or verbal behaviour as is the situation in general language'.

5. General language items which are utilized, in favour of other synonymous items, to illustrate or comment on technical processes and roles. For example, a study of biology textbooks proved that photosynthesis does not happen but takes place or occasionally occurs. Baker thus comments that take place and occur can be regarded as sub-technical words.

6. Items which are utilized in academic texts to carry out particular rhetorical roles. There are

(Baker, 1988, p. 92). 


\section{Lexical Inference as a Verbal Reasoning Strategy}

\subsection{Verbal Reasoning}

Verbal reasoning is one of four major cognitive reasoning skills. When the majority of people talk about learning,they are discussing the capacity of using verbal reasoning skills. Verbal reasoning includes making meaning relying on the information provided, going further that information to a better understanding, and using verbal skills to new learning. When speaking and listening are elements of verbal reasoning, the majority of formal verbal reasoning includes reading and writing (Donges, 2016, $\mathbf{\uparrow \uparrow}$. 1-2).

The verbal reasoning is related with the capacity of analyzing and evaluating written material, synthesize information got from it, and to identify connections between words and concepts ("Introduction to the verbal", 2009, p. $3)$.

Comprehension ofdiscourse is a main component in verbal reasoning. It includes the reader's existing knowledge, using information in discourse, and making inferences. The agreement of a quarter century of cognitive researchon reading describes it as an active process that includes constructing a mental representation of the text ("building meaning"), retrieving associated information from memory, assessing differences between text and the reader's prior knowledge, inferring required to fill blanks in understanding or making meaning clear, incorporate relevant novel information into the reader's knowledge (Burton, Welsh, Kostin, \& VanEssen 2009, p. 5).

One main background required for fluent reading is vocabulary. Accordingly, Lohman (2000) said that:

$$
\begin{aligned}
& \text {... vocabulary knowledge allows } \\
& \text { comprehension and expression of a broader } \\
& \text { array of ideas, which in turn facilitate the task } \\
& \text { of } \\
& \text { learning new words and... Thus, language } \\
& \text { functions as a vehicle for the expression...and } \\
& \text { acquisition of thought" (p. 319). }
\end{aligned}
$$

Models of comprehension are different; yet,various among them share alike ideas of the major cognitive elements and processes included in comprehension. Certain main ideas (related to memory network)adjusted by Graesser, Millis, and Zwaan (1997, pp. 174-5) are as follows:

1. The mental representation of the text, besides the reader's knowledge base, is

thought of as involving nodes, [derived from the Latin word for knot] interrelated byrelational ties or arcs (associations). The nodesmay be such things like concepts or things (Graesser \& Clark, 1985; van Dijk \&Kintsch, 1983). 
2. Nodes in the reader's knowledge base are stimulated when they are shown in text; thestimulation extends to relatively linked nodes in the knowledge base by means ofrelational arcs (Anderson,1983). Persistent reading may stimulate other nodes,boost the stimulationlevel of nodes formerly stimulated, or prevent nodes. For example, referring to bridge in text may stimulate a node for a buildingover a river and a second node for a card game; as reading continues, one of thesenodes will be suppressed (Gernsbacher, 1990; Kintsch, 1988, 1998). Nodes can be thought about as connected with cities, and associations as being the highways that relate the cities. Learning using this metaphor would be like constructing a highway between two cities, or may be developing an already being highway, for it can be more easily and rapidly visited. Here, some 'cities' are related by superhighways, others just by connecting country roads. Other cities are disconnected. This illustrate why certain memories are easily retrieved, while others are not (Reisberg, 2001, p. 236-7).

3. Different memory stores are involved in most reading models: short-term memory,working memory, and long-term memory. Short-term memory and workingmemory are considered to have restricted ability, just retaining the newest information being processed. Certain models have just one of these two; inmodels that have both, short-term memory has a smaller ability and workingmemory has some processing capacity, like recycling important information(Fletcher \& Bloom, 1988; Kintsch \& van Dijk, 1978; Trabasso \& Magliano, 1996).

4. A knowledge structure is reinforced (accessed more rapidly, remembered better) when:

- it is harmonious with other knowledge structures (a text can easily be incorporatedwith the reader's knowledge base if it suits the limits of the existing net ofnodes and relations ([Graesser \& Clark, 1985; Kintsch, 1988; MacDonald,Pearlmutter, \& Seidenberg, 1994]),

- the reader builds causal explanations for the content or presentation of thetext; for example, what may have caused the incident in a narrative or what thewriter means (Chi, de Leeuw, Chiu, \& LaVancher, 1994; Graesser et al.,1994; Pressley, Symons, McDaniel, Snyder, \& Turnure, 1988; Trabasso \&Magliano, 1996; Zwaan \& Brown, 1996), and

- it is frequently accessed.

(adapted by Chapman, 1993, pp. 16-7).

According to the book: Reading Framework for the 2003 NEAP (national assessment of education progress), for the purpose of reaching proficiency, readers "should be able to extend the ideas of the text by making inferences, drawing conclusions..." (p. 28). So what is inference/ lexical inferencing? 


\subsection{What is Lexical Inferencing}

Vocabulary inference is a cognitive process (knowledgeable guessing) L2 readers use to learn the meaning of new words. Lexical inferencing includes the aid of all accessible linguistic hints and other sources of information that the learner can use (Bogaards \&Laufer, 2004, p. 156). In this sense, Carton (1971) stated that inferencing is a process in which knowledge is used to distinguish what is unfamiliar, when he said that inferencing "is intended to refer to a process of identifying unfamiliar stimuli...Inferencing, attributes and contexts that are familiar are utilized in recognizing what is not familiar" (p. 45). Moreover, according to Haastrup (1991) lexical inferencing includes: "makinginformed guesses as to the meaning of a word in the light of all available linguistic cues in combination with the learner's general knowledge of the world, her awareness of the co-text and her relevant linguistic knowledge."(p. 13).

Lexical inferencing is a lot more than only 'guessing from context', since learners use their prior knowledge and the textual context to guess the significance of unfamiliar items. It would be better to consider lexical inferencing as being adequate guessing of the significance of lexical items in context, instead of guessing from, since contextual hints are just one of various information sources (Schmitt, 2010, p. 32). Hence, lexical inferencing is about guessing the meaning of unfamiliar words relying on different sources of knowledge.

\subsection{What Processes Are Involved in Lexical Inferencing?}

\subsubsection{Lexically Linked Frameworks}

\subsubsection{Knowledge Sources}

When L2 learners meet unfamiliar words, they would often try to find out the meaning by looking for their prior knowledge and information given in the text itself (Yang, 2014, pp. 20-1).

Carton (1971) distinguished three major sources of knowledge that foreign language learners might use in lexical inferencing: contextual, intralingual, and interlingual (Chavosh \& Davoud, 2016, p. 45). Haastrup (1991) used the same classification (Akpinar, 2013, p. 2). While using contextual hints (extralingual or pragmatic hints), learners use their knowledge of the world and the co-text. Knowledge of the world involves factual knowledge, viewpoints, and convictions (Akpinar, 2013, p. 2). From the other side, the function of co-text has to do with how the understanding of a lexical item is influenced by the particular linguistic context in which it is put. In order that contextual hints can be useful for word inference, Li (1988) demonstrated that primarilycontextual hintsshould be common to the reader. Secondly, they must involve the information being in the text to get the associated schemata for the purpose of explaining the subsequent input in the text and notice the 
uncommon stimuli. In the absence of such hints, inferencing may end in guessing inappropriately (bensoussan \& Laufer, 1984). They end up that lexical guessing is a so hard activity because of the text difficulty or the constraints of the reader, or the two of them (Chavosh \& Davoudi, 2016, p. 45).

\subsubsection{Lemma Construction}

De Bot, Paribakht, \& Wesche (1997) claimed that the reader's first notice of the form of unknown word may guide to generating of an "empty knowledge structure and a new lemma" (p. 317). Lexical inferencing within this framework can be seen as the process of trying to plug this knowledge structure for a novel word or meaning for a familiar word. Recognizing lemma information includes exploring and using several knowledge sources from textual hints and prior knowledge, guided by characteristics of the word information constituents of the mental lexicon. The lemma seeking may stimulate a lemma present in the reader's L1, L2 (or Ln) mental lexicon that he/ she may link to the novel lexeme, like that of a close L2 synonym or a supposed lexical corresponding in the learner's L1or another familiar language.Hence, evena slightlyproper lemma will ease comprehension(Wesche \& Paribakht, 2010, pp. 20-21).

The lexeme/ lemma difference help illustrate the relationship between the readers view of the novel word form (its orthographic and morphological aspects) and comprehension of a novel word's meaning via inferencing (Wesche \& Paribakht, 2010, p. 21).

\subsubsection{Connectionism}

Connectionism is a current broadly taken demonstration of the basic cognitive mechanism causing the accessing and development of knowledge. In connectionist models, access to knowledge includes parallel stimulation by different processors as knowledge of a word is represented in a dispensed means, available as models of stimulation at the level of sub-lexical aspects instead of a united lexical access (Wesche \& Paribakht, 2010, p. 21).

Henriksen (2008), in her research about the way networks may be acquired and stimulated, stated:

[the] creation of links between the various lexical items is a continuous process of expansion and restructuring as words occur in different contexts and new items are added to the lexical store. [Some associative]links may be weakened by lack of activation. “...”" (p. 28)

\subsubsection{Cognitive Theory in Comprehension and Acquisition Outcomes of} Lexical

\section{Inferencing}

Gass (1988, 1997) input processing framework offers a practical viewpoint of lexical acquisition. This framework has shown beneficial in setting the lexical inferencing process in association with word and text 
comprehension (Paribakht \& Wesche, 1996; Wesche \& Paribakht, 2000). As used in word learning via reading, the framework follows learners 'input processing' from first apperception (remarking) of a novel word form in the L2 information they read and its link with prior knowledge, via the comprehension of a meaning in the context (a process that may include lexical inferencing), to intake/ assimilation of some mental representation of the word form and its related meaning (as restricted by the type of analysis throughout elementary comprehension), to the potential integration of all or piece of this representation into prior knowledge structures. Ultimate internalized accessibility of the novel knowledge representation for retrieval and productive use by the learner may itself help in the transformation of more comprehended information to assimilate (Wesche \& Paribakht, 2010, pp. 24-5).

Throughout frequent experiences with the word including assimilation and incorporation of novel lexical knowledge, the learner builds on a growing detailed mental representation of the word's phonological and orthographic form, its meaning (s), its syntactic limitations, its network associations, and other types of knowledge about it, and a gradually easy access to it in comprehension and production (Wesche \& Paribakht, 2010, p. 26).

Lately, the concept of vocabulary network knowledge and very linked structures, like structural knowledge and depth of vocabulary knowledge, have improved our understanding of the mental lexicon and how it grows (Wesche \& Paribakht, 2010, p. 26).

\subsection{Second Language Inferring Word Meaning from Context}

When it comes to second language reading (e.g. Carton, 1971; honeyfield, 1977; Nation and Coady, 1988), most of the variables relevant to L1 readers apply to L2 readers too. One variable that is particularly relevant to L2 readers is the degree of competency in the language. The reader will not be capable of making contextual hints in the text becausethe words which give such hints for a specific target wordare themselves unfamiliar. Laufer (1992, 1997) states that second language readers of English are required to have a minimum of 3000 word families to have certain knowledge of $95 \%$ of the words in the text. This way, the concentration of unfamiliar words lessens to 1 in 20 (Read, 2000, p. 56).

Writers on lexical inferencing usually give the impression that, with such a broadscope of contextual hints available, each unfamiliar word will have certain hints, if just the reader learns the way to reach and understand them. This positive viewpoint is strengthened by practice, in investigation and in course books for learners, of exhibiting target words in contexts which have been selected, written to give hints for the purpose of giving the learners a good opportunity of guessing the words effectively. Yet, the findings of certain studies propose vigilance; in their study of lexical guessing by students learning English as a foreign language at a university in Israel, Bensoussan and 
Laufer (1984) chose 70 target words from atext of about 600 words. The examiners found that there were no contextual hints for $29(41 \%)$ of them, when just $13(19 \%)$ of the rest ones could be said to be cued by the text.The main idea is that we should not presume that the context unavoidably facilitates understanding the meaning of words unknown to the readers (Read, 2000, pp. 57-8).

Another important question about lexical guessing is about how effective learners are if they have not been particularly trained to do it. Many studies (Bensoussan \& Laufer, 1984; Haynes, 1984; Laufer \& Sim, 1985)have shown that learners quite usually make incorrect guesses that are the consequence of providing the wrong sense of a word that has various senses, mistake the target word with another alike form or sound ('uniquely' interpreted as ' unequally'), etc.Liu and Nation (1985) report that the majority of learners would require a significant exercise in class, with the assistance of the teacher, before being capable of guessing effectively when reading alone (Read, 2000, p. 58).

Other researchers have concentrated on the processes that foreign language learners use when attempting to infer the meanings of unfamiliar words in a text. Van Parrenren and Schouten- Van Parrenren (1981) distinguished four linguistic degrees at which the learners could function: syntactic (structure of the sentence), semantic (meaning in the instant and broader context of the word), lexical (form of the word), stylistic (the precise using of this word in this context). They reached the conclusion that the degrees were arranged from syntactic to stylistic as the highest. This means that learners could not work at a higher level if lower level skills were missing (Read, 2000, pp. 58-9).

Again, proof is that lexical guessing is not a simple activity to perform, even if contextual information is easily accessible. Learners can deviate through inferences by their failure to verify their initial guesses in comparison with the broader context of the text (Read, 2000, pp. 59- 60).

Studies on lexical inferencing in the L2 have stressed various features of the process. Primarily, it has been shown that L2 readers do not try to guess the meaning of unknown items all the time (e.g. Bensoussan \& Laufer, 1984; Parry, 1993), mainly if they think the word does not have vital significance for text comprehension. Other studies have shown that the capacity of making a successful guess is very changeable (Haastrup, 1991; Paribakht \& Wesche, 1999) (Prior et al., 2014, pp. 2-3).

It is logical to presume that an important part of vocabulary learning in L2 happens incidentally from reading new words in context (Gass, 1999). Yet, the effectiveness of incidental vocabulary learning and lexical inference from reading in L2 is, yet, at the heart of investigation (Huckin \& Coady, 1999; Wesche \& Paribakht, 2010) (Prior et al., 2014, p. 3). 
There is a significant inconsistency in researches in the revealed ability of $L 2$ readers to infer the meaning of unknown words from text, even in case the related context sustains those inferences (Bensoussan \& Laufer, 1984; Haynes, 1993; Haynes \& Baker, 1993; Huckin \& Bloch, 1993; Knight, 1994; Pulido, 2007) (Prior et al., 2014, p. 3).

A significant factor participating in the capacity of inferring the meaning of words from written context for L2 learners is competency in the language. But the concept of competency is intricate, and may involve various main language skills besides vocabulary and morphosyntactic knowledge (lesaux \& Kieffer, 2010), yet word reading fluency too (Seipel, 2011) (Prior et al., 2014, p. 3).

\section{Hypothesis}

We hypothesize that if EFL third year learners would use their cognitive capacities of inferring technical terms (in the field of Psychopedagogy), then they would enhance their learning (and retaining) of the latter vocabulary.

\section{Participants}

\section{Method}

The subjects involved in this study were composed of twenty (20) learners from an entire population of about 220 undergraduate third year students ( $3^{\text {rd }}$ year) at the University Frères Mentoury/ Constantine1, in 2014. The learners are supposed to have basic knowledge of English words and sentences - enough to read simple texts.

\section{Tools and Procedures}

The material used in this study included Three (03) cloze procedure activities, where the selected texts, about Psycho-pedagogy, were not long (no more than 350 words in length) and simple. The texts are about the different types of memory, Piaget's sensorimotor stages of cognitive development, and Maslow's hierarchy of human needs. The words deleted are academic terms (technical) that have been taught to students during the year in this module. 
Imane LAMRI

3. Results: interpretation and discussion

3.1. Analysis of the students'answers/Memory Types

\begin{tabular}{|c|c|c|c|c|c|c|c|}
\hline \multirow[t]{2}{*}{ Item } & \multicolumn{2}{|c|}{$\begin{array}{l}\text { Right } \\
\text { Answer }\end{array}$} & \multicolumn{2}{|c|}{$\begin{array}{l}\text { Wrong } \\
\text { Answer }\end{array}$} & \multicolumn{2}{|c|}{$\begin{array}{l}\text { No } \\
\text { Answer }\end{array}$} & \multirow[t]{2}{*}{ Total } \\
\hline & $\mathrm{N}$ & $\%$ & $\mathrm{~N}$ & $\%$ & $\mathrm{~N}$ & $\%$ & \\
\hline Sensorymemory & 17 & 85 & 03 & 15 & 00 & 00 & 20 \\
\hline Five senses & 17 & 85 & 03 & 15 & 00 & 00 & 20 \\
\hline Stimuli & 16 & 80 & 04 & 20 & 00 & 00 & 20 \\
\hline Sensory memory & 02 & 10 & 18 & 90 & 00 & 00 & 20 \\
\hline $\begin{array}{l}\text { Short-term } \\
\text { memory }\end{array}$ & 16 & 80 & 04 & 20 & 00 & 00 & 20 \\
\hline Attention & 09 & 45 & 11 & 55 & 00 & 00 & 20 \\
\hline Stimuli & 03 & 15 & 15 & 75 & 02 & 10 & 20 \\
\hline $\begin{array}{l}\text { Long-term } \\
\text { memory }\end{array}$ & 16 & 80 & 04 & 20 & 00 & 00 & 20 \\
\hline Limited capacity & 14 & 70 & 06 & 30 & 00 & 00 & 20 \\
\hline Rehearsal & 14 & 70 & 06 & 30 & 00 & 00 & 20 \\
\hline $\begin{array}{l}\text { Long-term } \\
\text { memory }\end{array}$ & 19 & 95 & 01 & 05 & 00 & 00 & 20 \\
\hline Unlimited & 18 & 90 & 01 & 05 & 01 & 05 & 20 \\
\hline $\begin{array}{l}\text { Short-term } \\
\text { memory }\end{array}$ & 17 & 85 & 01 & 05 & 02 & 10 & 20 \\
\hline Mean & 13,69 & 68,45 & 06 & 30 & 0,38 & 01,92 & \\
\hline
\end{tabular}

Table 01:Summary Table of the Cloze Procedure Format (Memory)

The table indicates that the learners' responses vary from one item to another, and even for the same item (the proportions of correct and/ or wrong responses are different for items that appear twice in the passage). The highest proportion of the learners' correct answer represents 95\%, and the lowest proportion represents $10 \%$, whereas the proportion of incorrect answers vary from $90 \%$ to $5 \%$. We should state also that some learners (between $10 \%$ and $5 \%$ ) provided no answers to some items.

Totally, about $30 \%$ provided wrong answers against $68,45 \%$ who gave correct answers. 
A Study of Verbal Reasoning and ESL Vocabulary Learning from a Psycholinguistic Perspective

3.2. Analysis of the students' answers/Maslow's Hierarchy of Human Needs

\begin{tabular}{|c|c|c|c|c|c|c|c|}
\hline \multirow[t]{2}{*}{ Item } & \multicolumn{2}{|c|}{$\begin{array}{c}\text { Right } \\
\text { Answer }\end{array}$} & \multicolumn{2}{|c|}{$\begin{array}{l}\text { Wrong } \\
\text { Answer }\end{array}$} & \multicolumn{2}{|c|}{ No Answer } & \multirow[b]{2}{*}{ Total } \\
\hline & $\mathrm{N}$ & $\%$ & $\mathrm{~N}$ & $\%$ & $\mathrm{~N}$ & $\%$ & \\
\hline $\begin{array}{l}\text { Physiological } \\
\text { Needs }\end{array}$ & 14 & 70 & 06 & 30 & 00 & 00 & 20 \\
\hline Physiologicalneeds & 16 & 80 & 04 & 20 & 00 & 00 & 20 \\
\hline Deficiencyneeds & 09 & 45 & 11 & 55 & 00 & 00 & 20 \\
\hline Aesthetic & 11 & 55 & 09 & 45 & 00 & 00 & 20 \\
\hline Self-actualization & 14 & 70 & 06 & 30 & 00 & 00 & 20 \\
\hline Self-actualization & 09 & 45 & 11 & 55 & 00 & 00 & 20 \\
\hline Self-actualization & 09 & 45 & 09 & 45 & 02 & 10 & 20 \\
\hline Growth needs & 12 & 60 & 07 & 35 & 01 & 05 & 20 \\
\hline Mean & 11,75 & 58,75 & 07,87 & 39,37 & 0,37 & 01,87 & \\
\hline
\end{tabular}

Table 02:Summary Table of the Cloze Procedure Format (Maslow's theory of needs)

The table indicates that the learners' responses vary from one item to another, and even for the same item (the proportions of correct and/ or wrong responses are different for items that appear twice in the passage). The highest proportion of the learners' correct answer represents $80 \%$, and the lowest proportion represents $45 \%$, whereas the proportion of incorrect answers vary from $55 \%$ to $20 \%$. We should also state that some learners (between $10 \%$ and $5 \%$ ) provided no answers to some items.

Overall, about $39,37 \%$ provided wrong answers against $58,75 \%$ who gave correct answers. And 1,87\% had no answer. 
Imane LAMRI

3.3Analysis of the student's answers/ Piaget's Stages of Cognitive Development: Adaptation

\begin{tabular}{|c|c|c|c|c|c|c|c|}
\hline \multirow[t]{2}{*}{ Item } & \multicolumn{2}{|c|}{$\begin{array}{l}\text { Right } \\
\text { Answer }\end{array}$} & \multicolumn{2}{|c|}{ Wrong Answer } & \multicolumn{2}{|c|}{ Answer $\quad$ No } & \multirow[t]{2}{*}{ Total } \\
\hline & $\mathrm{N}$ & $\%$ & $\mathrm{~N}$ & $\%$ & $\mathrm{~N}$ & $\%$ & \\
\hline Schemes & 11 & 55 & 04 & 20 & 05 & 25 & 20 \\
\hline Adaptation & 20 & 100 & 00 & 00 & 00 & 00 & 20 \\
\hline Assimilation & 19 & 95 & 01 & 05 & 00 & 00 & 20 \\
\hline Scheme & 20 & 100 & 00 & 00 & 00 & 00 & 20 \\
\hline Scheme & 20 & 100 & 00 & 00 & 00 & 00 & 20 \\
\hline Accomodation & 11 & 55 & 03 & 15 & 06 & 30 & 20 \\
\hline Schemes & 21 & 90 & 02 & 10 & 00 & 00 & 20 \\
\hline Mean & 17,4 & 85 & 01, & 07,14 & 01,5 & 07,85 & \\
\hline
\end{tabular}

Table 03:Summary Table of the Cloze Procedure Format (how cognitive development occurs)

The table indicates that the learners' responses vary from one item to another, and even for the same item (the proportions of correct and/ or wrong responses are somewhat different for items that appear several times in the passage). The highest proportion of the learners' correct answer represents $100 \%$, and the lowest proportion represents $55 \%$, whereas the proportion of incorrect answers vary from $0 \%$ to $20 \%$. We should state also that some learners (between 25\% and 30\%) provided no answers to some items.

In general, about $7,14 \%$ provided wrong answers against $85 \%$ who gave correct answers. And 7,85\% had no answer. And among those who provided "scheme" as correct answer, many added the "s" of the plural when the item takes the singular form and the opposite. This is related to Grammar competence.

\subsection{Discussion}

The results obtained show that the highest percentages of wordmeaning inference are related to the correct answers in the passage $(68 \%, 58 \%$, $85 \%$, successively). The participants seem to use a combination of different kinds of knowledge to get a successful guess; Comer (2012) mentioned that L2 readers use a range of knowledge sources to infer the meanings of unknown words (Bengeleil \& Paribakht, 2004; de Bot, Paribakht, \& Wesche, 1997; Fraser, 1999; Haastrup, 1987, 1991; Morrison, 1996; Nassaji, 2003b; Paribakht \& Wesche, 2006; Wesche \& Paribakht, 2010, cited in Comer, 2012, p. 210). The latter include contextual cues (context), linguistic knowledge involving: word-level knowledge (like morphology, schema, cognates, associations, etc) and syntactic knowledge (sentence-level knowledge: parts of speech, sentence meaning, sentence syntax, and punctuation), besides background knowledge 
that includes: prior knowledge about a word, and knowledge of the world (facts, viewpoints, convictions).

Concerning using the morphology category, technical terms are resistant to change; they are statique words that do not take inflectional or derivational forms, etc. Yet, considering the levels of technicalness, learners can guess some meanings of the terminology when related to words which are used in general language and, hence, are easily understood out of the study field. For example, $100 \%$ of the participants accurately inferredthe word adaptation. Moreover, $90 \%$ among them made the right guess for Unlimitedwhich is among the terms which are called sometimes sub-technical words andwhich is minimally connected to the field of Psychopedagogy.Also, syntactic knowledge seems to work well. At the sentence level, many learners might have relied on the semantic definitions of the terminology to provide a correct inference, like with the term assimilation which appears in the sentence "(Assimilation) is the process of understanding a new object...in terms of an existing scheme", in which the learners reached $95 \%$ of correct answers. In addition to that, the role that memory can play to help make successful guess is an undeniable factor.Despite the fact that memory has a limited capacity, learners have more or lesslearnt definitional meanings via explanations through the lectures; what makes them familiar with the topics in the passages,andpermits them to create background knowledge (semantic representations of the new concepts/ technical terms)as a knowledge source that influenceslexical inference and its outcomes. However, for lexical inference, the role of these knowledge sources at different levels of L2 language proficiency remains an area of ongoing research.

As for the learners who failed to make correct guesses, they might have bad memory capacities or have learnt the concepts yet are not ready to meet them in different contexts. Moreover, they, may be, have poor reading comprehension skills which make it difficult to use the clues in the texts.

\section{Conclusion}

This study seems to provide some evidence that using lexical inference, as a cognitive skill, while reading for comprehension is a useful strategy that helps constructing accurate semantic representations of ESL technical terms; hence,learners are required to improve this capacity (besides nonreflective strategies like simple memorization, repetition) to build new vocabularies (L2 words generally and technical terms specifically) as important component of the language that the learners need to learn, especially because learning a second language lexicon is not an easy matter; as many internal factors like the L1, the organization of the mental lexicon, memory (besides external factors like teaching strategies) are involved to make it more or less difficult. 
In addition, teachers are required to help learners develop their lexical inference competence since inferring is anintricate strategy needing important active treatment of information (Cohen \& Aphek, 1981, cited in Schmitt, 2000, pp. 132-3).

However, the actual study does not provide further evidence to confirm that the words were actually grasped by the participants, besides that the number of the participants is limited in relation to the population of third year learners having the module of Psychopedagogy (it equals around 700 learners in 2014). Also, the number is related in relation to place (only one university is involved).

\section{List of References}

(1)-Akpinar, K. D. (2013). Lexical inferencing: perceptions and actual behaviours ofTurkish English as a foreign language learners' handling of unknown vocabulary. SouthAfrican Journal of Education, 33 (3). 1-4.

(2)-Ausubel, D.P. (1967). Learning theory and classroom practice.Toronto: Ontario Institute for Studies in Education.

(3)-Baddeley, A. D. (1997). Human memory: theory and practice. Hove: Psychology Press.

(4)-Baker, M. (1988). Sub-technical vocabulary and the ESP teacher: an analysis of some rhetorical items in medical journal articles. Reading in a

Foreign Language, 4 (2), 91-105.

(5)-Bogaards, P., \& Laufer, B. ( Eds.) (2004). Vocabulary in a Second Language. Selection, acquisition, and testing. Amsterdam: John Benjamins Publishing Company.

(6)-Burton, N.W., Welsh,C., Kostin, I., \& VanEssen, T. (2009). Toward a Definition of Verbal Reasoning in Higher Education. Research Report [PDF file].Educational TestingService.Retrieved 26 October 2016, from http://www.files.eric.ed.gov/fulltext/ED507807.

(7)-Carton A. S. (1971). Inferencing: a process in using and learning language. In P. Pimsleur \& T. Quinn (Eds.), The Psychology of Second Language Learning. Cambridge: Cambridge University Press.

(8)-Chapman, A. (Ed.). (1993). Making Sense: Teaching Critical Reading Across the Curriculum. New York: The College Board.

(9)-Chavosh, M., \& Davoud, M. (2016). The effect of explicit teaching of lexical inferencing strategies on vocabulary learning among Iranian fielddependent an independent EFLlearners. Studies in Literature and Language, 12 (4), 44-53.

(10)-Comer, W.J. (2012). Lexical Inferencing in Reading L2 Russian [PDF file]. Reading in a Foreign Language, 24 (2), 209-30. 
(11)-Donges, C. (2016). What is Verbal Reasoning and How Does it Affect Learning. Retrieved 27October2016, from http/: www.Classroom.synonym.com.

(12)-Fan, M. (2003). Frequency of use, perceived usefulness, and actual usefulness of second language vocabulary strategies: A study of Hong Kong learners. The Modern Language Journal, 87(2), 222-41.

(13)-Grasser, A.L., Millis, K.K., \& Zwaan, R.A. (1997). Discourse comprehension. Annual Review of Psychology, 48 (1), 163-89.

(14)-Haastrup, K. (1991). Lexical Inferencing Procedures or Talking About Words: Receptive Procedures in Foreign Language Learning With Special Reference to English. Tubingen, Germany: Gunter Narr.

(15)-Henriksen, B. (2008). Declarative lexical knowledge. In D. Albrechtsen, K. Haastrup, \& B. Henriksen (Eds.), Vocabulary and Writing in a First and Second Language: Processes and Development. Basingstoke: Palgrave Macmillan.

(16)-Hulstijn, J. H. (2000). Mnemonic methods in foreign language vocabulary learning: theoretical considerations and pedagogical implications. In J. Coady \& T. Huckin (Eds.), Second Language Vocabulary Acquisition(pp. 203-24). Cambridge: Cambridge University Press.

(17)-Introduction to the Verbal Measure [PDF file] (2009). Retrieved

270ctober, 2016, from http://www.ets.org/.../GRE.Intro_Verbal_18.point.p.... (18)-Lewis, M. (1993). The Lexical Approach. Hove, England: Language Teaching Publications.

(19)-Lohman, P.F. (2000). Complex information processing and intelligence.

In R.S. Sternberg (Ed.), Handbook of Intelligence. Cambridge: Cambridge University Press.

(20)-McCarthy, M., Okeeffe, A., \& Walsh, S. (2010). Vocabulary Matrix. Understanding, Learning, Teaching. Hampshire (UK): HEINLE, CENGAGE Learning.

(21)-Milton, J. (2009). Measuring Second Language Vocabulary Acquisition.

Bristol, UK: Multilingual Matters.

(22)-Mudraya, O. (2006). Engineering English: a lexical frequency

instructional model. English for Specific Purposes, 25 (2), 238-39.

(23)-Nation, I. S. P. (2001). Learning Vocabulary in Another Language.

Cambridge: Cambridge University Press.

(24)-Nation, P., \& Gu, P. (2007). Focus on Vocabulary. Sydney: NCELTR.

(25)-Nippold, M. (2004). Research on later language development: international perspectives. In R. A. Berman (Ed.), Language development across childhood and adolescence (pp. 1-8). Amsterdam: John Benjamins.

(26)-Paquot, M. (2010). Academic Vocabulary in Learner Writing. London: Continuum International Publishing Group. 
(27)-Prior, A., Goldina, A., Shany, M., Geva, E., \& Katzir, T. (2014). Lexical Inferencing in L2: Predictive Roles of Vocabulary Knowledge and Reading Skill Beyond Reading Comprehension [PDF file]. Retrieved 3August2016, from http:// www. Research gate.net/

(28)-Read, J. (2000). Assessing Vocabulary. Cambridge: Cambridge University Press.Reading Framework for the 2003 National Assessment of Educational Progress (2002). Washington: NA Governing Board. (US Department of Education).

(29)-Reisberg, D. (2001). Associative theories of long term memory. Cognition. Exploring the Science of the Mind. $2^{\text {nd }}$ ed. New York: W.W. Norton \& Company.

(30)-Schmitt, N. (2000). Vocabulary in Language Teaching. Richards, J. C. (Ed.). Cambridge: Cambridge University Press.

(31)-Schmitt, N. (2010). Researching Vocabulary. A Vocabulary Research Manual. London:Palgrave macmillan.

(32)-Strazny, P. (Ed.). (2005). Encyclopedia of Linguistics. V 1\&2. New York: FITZROY DEARBORN.

(33)-Swan, M. (1997). The influence of the mother tongue on second language vocabulary acquisition and use. In N. Schmitt \& M. McCarthy (Eds.), Vocabulary: Description, Acquisition and Pedagogy(pp. 156-80). Cambridge: Cambridge University Press.

(34)-Takac,V. P. (2008). Vocabulay Learning Strategies and Foreign Language Acquisition.Toronto (Canada): MULTILINGUAL MATTERS LTD.

(35)-Wesche, M. B., \& Paribakht, T. S. (2010). Lexical Inferencing in a First and Second Language. Cross Linguistic Dimensions. Bristol: MULTILINGUAL MATTERS.

(36)-Yang S. L. (2014). How Advanced EFL Taiwanese Learners Infer Meanings of Unknown Words While Reading[PDF file]. Retrieved 20 August 2016, from http//: www. 140.127.82.166/retrieve/23100/019. 